\title{
Report to the Executive Committee
}

\author{
by the Strategy Development and Implementation Committee
}

\section{Proposed changes in organization and management of IUPAC scientific activities}

The final report by the Strategy Development and Implementation Committee (SDIC) is given in the following pages The IUPAC Executive Committee has accepted the SDIC report and voted unanimously to recommend to the Bureau that the proposals by the SDIC be adopted. The Strategic Plan, 1998-99. has already been approved by the IUPAC Executive Committee. The recommended changes in organization and management that will occur are far-reaching and will alter many aspects of the IUPAC structure and operations. I strongly believe that these proposals should be implemented and will enable the Union to play a major role in the development of chemistry in the 21 st century.

Under the SDIC proposals, the seven Division Committees will assume direct responsibility for initiating, developing and managing the Union's scientific work, with each scientific project carried out by a short-term Task Group. Allocation of financial resources is to be tied directly to individual projects, and meaningful dates are to be established for completion of projects. These proposals thus envision a structure that is far more dynamic than the present one with 37 relatively permanent Commissions. In fact, the SDIC recommends that Council be asked in 1999 to terminate all existing Commissions at the end of 2001 and permit a smaller number of new Commissions to be formed as planning and advisory bodies when needed.

The SDIC has considered in considerable detail just how ideas for new projects can be generated and individuals recruited to carry out the projects in the absence of a large cadre of Commission members. We expect to reach out to the world-wide chemistry community and anticipate that National Adhering Organizations will become more actively involved in project generation and in suggesting scientists to serve on Task Groups. During the next three years the current Commissions, in collaboration with their Division Committees, will play a central role in defining areas of science that need study by IUPAC and in proposing specific projects and individuals who might carry out such projects.

The Bureau will be asked to approve in September a major new policy for IUPAC's future development. Prior to that time it is important that we have a wide-ranging discussion within the Union of the details and ramifications of these proposals. The report by the SDIC is comprehensive and provides detailed explanations for the recommendations that are made. Nevertheless, there are undoubtedly some aspects that have not been considered and some consequences of the proposals that have not been fully appreciated. We begin now to solicit views from the National Adhering Organizations that provide the resources for our activities; from the many people who carry out the work within the Union; and from the world-wide community of chemists and the chemical industry, whom we ultimately serve.

I would appreciate receiving your comments and questions. They should be submitted through the Secretariat, either by e-mail: secretariat@iupac.org, or at the address given on the inside front cover.

\section{Joshua Jortner, President, IUPAC}

\section{Executive Summary}

The Strategy Development and Implementation Committee (SDIC) was established by the IUPAC Executive Committee (EC) on 7 April 1997 with the following charge:

1 Develop long-range goals or mission statements, based initially on the recommendations in the 1997 Vice-President's Critical Assessment.

2 Propose strategies for achieving these goals.

3 Examine the feasibility of converting the bulk of IUPAC's scientific work to a project-driven system, with time-limited Commissions, as expressed in the concept endorsed by the EC.

4 Propose specific means by which this concept (if found feasible) can and should be implemented, with desirable target dates.

The SDIC completed tasks 1 and 2 at the end of 1997 and submitted a proposed Strategic Plan to the Executive Committee (EC) in January 1998. This Plan, which is also presented and described in this report, was approved by the EC and has been widely disseminated. The Strategic Plan provides a succinct statement of IUPAC's Mission, a statement of 10 long-range Goals 
and a set of Strategies to achieve each Goal. The Plan constitutes a declaration of the Union's global policy. It also provides a guide to the development of operational programs and a set of criteria against which to evaluate the accomplishments of IUPAC bodies.

Tasks 3 and 4 refer to changes in operational policies and procedures that would significantly change many aspects of the way in which the Union carries out its scientific activities. Since these activities are carried out primarily through the Divisions and Commissions, the SDIC has directed its attention to these bodies, not to the Bureau and Standing Committees, which have responsibilities in other areas. The SDIC has concluded that it is feasible to convert the Division/Commission structure and operations into one that focuses largely on specific projects carried out by time-limited bodies. However, the SDIC believes that successful operations in the future require the implementation of a number of concurrent changes. The SDIC has developed an integrated program to refocus IUPAC's efforts, to insure continuing quality and expertise in its scientific leadership, and to involve the world-wide chemistry community in the development and conduct of the Union's projects.

The following steps must be taken in concert to achieve the desired goals:

- Each Division Committee will become the clear focus in its branch of chemistry for the initiation of scientific efforts and for the development and management of individual projects. The duties of the Division Committees will be redefined; the membership augmented as needed to provide sufficiently broad scientific expertise; and the mechanism for nominating members of Division Committees modified to insure a continuing source of top-notch leadership drawn widely from the world's chemists.

- Ideas for projects will be solicited widely from National Adhering Organizations, national and regional chemical societies, industrial organizations and the general chemistry community. Proactive efforts will be made to assess needs for IUPAC action through presentations and discussions at IUPAC-sponsored symposia and other specialized meetings in the chemical sciences.

- It is expected that most projects will be carried out by Task Groups appointed for the (usually short-term) duration of the project and funded adequately to permit completion of the project in the planned time frame.

- The professional staff of the Secretariat will be developed to provide assistance to the Task Groups as needed and to assist in seeking ideas for IUPAC projects. The Secretariat staff will help to develop new projects and will actively seek outside funding when appropriate.
- In 1999 at Berlin, Council will be asked to amend Bylaw 4.307, effective 1 January 2002, to remove the 'right' of Titular Members to receive funds for travel and subsistence. Expenses will henceforth be paid as needed to accomplish particular objectives-e.g. to plan a program, provide advice to the Division Committee or carry out a project. By eliminating these automatic expenditures, the SDIC believes that a significant fraction of the $\$ 525000$ budgeted for each General Assembly and funds allocated for 'even year' meetings of Commissions can be redirected to high priority projects.

- In 1999 at Berlin, Council will be asked to terminate all existing Commissions on 31 December 2001. Requests by the Divisions to form new Commissions, for operation in 2002 and beyond, primarily as long-range planning and advisory bodies, will be considered by the Bureau and by Council in 1999 and 2001.

The SDIC anticipates that this report will be widely read and discussed within IUPAC and by its National Adhering Organizations. Hence, the body of the report and the appendices contain considerable background information. Furthermore, the presentation of recommendations is often rather detailed in order to provide an indication of the thorough discussion by the SDIC and of the rationale for each proposal. The financial implications of the Strategic Plan and the recommended operational changes are discussed and shown to require no additional resources.

A more succinct presentation of the recommendations and a timetable for actions is given on pp. 22-24. The SDIC recommends that the EC approve this program, request comments from IUPAC bodies and the Union's National Adhering Organizations, modify the details as needed as a result of comments received, and submit the proposal to the Bureau for action. The Bureau will be asked to endorse this program in September 1998 and set in motion the steps outlined above.

\section{Table of contents}

\begin{tabular}{lr}
\hline Executive Summary & 55 \\
Formation of the SDIC & 57 \\
Background & 57 \\
Charge to the SDIC & 58 \\
Membership & 58 \\
Committee meetings & 58 \\
Strategic Plan & 58 \\
Preamble & 58 \\
Mission Statement & 59 \\
Long-range goals & 59 \\
Goals and strategic thrusts-1998-1999 & 59 \\
Implementation and updating of the Strategic Plan
\end{tabular}


Organization and management of scientific work

Responsibilities of division committees Election of division committees and division officers

Nominating Committee

Nominees for Division Committee

Size of Division Committees

Division Officers

Project-driven system

Current status of Commissions

Proposed funding for Commissions

Formation and termination of Commissions

National Representatives

Conversion to a new project-driven system

Operation of a project-driven system

Sources of ideas

Personnel to carry out projects

Project development and management

Evaluation of projects

Prospective evaluation

Retrospective evaluation

Role of the Secretariat

Financial considerations

Summary of recommendations on organization and management of scientific activities

A Division Committee

B Commissions

C Secretariat

D Funding

Summary of formal actions required

Concluding statement

Appendices

1 Membership of the SDIC

2 Initially suggested goals and mission statements

3 Secretary General's Report Organization and man-

agement of IUPAC's scientific work

4 Selected bylaws

\section{Report to the Executive Committee by the Strategy Development and Imple- mentation Committee}

The Strategy Development and Implementation Committee (SDIC) was established by the IUPAC Executive Committee (EC) on 7 April 1997 as an ad hoc committee with the charge given below and instructions to report to the EC before its meeting in April 1998. Members of the SDIC were appointed by the President of IUPAC, as described below. This document constitutes the final report by the SDIC in fulfillment of its mission.

\section{Formation of the SDIC}

\section{Background}

During 1996 and 1997, the Officers of IUPAC undertook efforts to solicit opinions from the world-wide chemistry community on the future role of IUPAC. Out of the conferences held in the USA in June 1996 and in London in February 1997 (later reinforced by the conference held in Singapore in June 1997), there emerged many specific ideas for future developments of the Union, but there were three overriding major points: (i) IUPAC needed to develop an updated Mission in order to regain relevance to the international community of chemistry and the chemical industry; (ii) the Objectives given in IUPAC Statute 1 should be augmented by specific, achievable Goals; and (iii) IUPAC should broaden the geographic base of the Union's activities to achieve its full potential as a global organization. These concepts formed part of the underpinning of the statutory VicePresident's Critical Assessment (VPCA), and VicePresident Jortner proposed a number of specific goals. In April 1997 the EC endorsed the general thrust of these proposed goals but recognized that they needed to be considered carefully and fleshed out into a Strategic Plan for the Union.

Meanwhile, the organization and management of IUPAC's scientific work had been the subject of extensive discussion and debate within the Union over a period of several years. There was general recognition that the relatively static Commission structure is outdated and that it is inadvisable to spread IUPAC's limited resources among seven Divisions and 37 Commissions, which attempt to carry out nearly 500 projects concurrently. Various proposals had been advanced for restructuring Divisions and Commissions, and great efforts had gone into developing a scientific policy for the Union. Options for restructuring and for allocating resources by project were discussed in detail at the annual Division Presidents meeting in September 1996 and at a special meeting of Division Presidents and Vice-Presidents in March 1997. It was clear that the Divisions wanted and needed more flexibility in managing their programs. Against this background, the Secretary General prepared a paper for the EC meeting in April 1997 that advocated an emphasis on funding projects that would be carried out primarily by time-limited Commissions. After much discussion, the EC endorsed this concept but recognized that the proposed major changes in the organization and management of the Union's scientific work needed considerable further study and analysis.

The EC decided therefore that the separate but related issues of formulating long-range goals and strategies and of implementing the management changes needed to achieve the goals could best be addressed by a single broad-based ad hoc committee, the SDIC. 


\section{Charge to the SDIC}

The charge to the SDIC is as follows:

1 Develop long-range goals or mission statements, based initially on the recommendations in the 1997 Vice-President's Critical Assessment.

2 Propose strategies for achieving these goals.

3 Examine the feasibility of converting the bulk of IUPAC's scientific work to a project-driven system, with time-limited Commissions, as expressed in the concept endorsed by the EC.

4 Propose specific means by which this concept (if found feasible) can and should be implemented, with desirable target dates.

The SDIC is to report to the EC in time for its meeting in April 1998.

\section{Membership}

To assure that all facets of the Union's programs would be considered by the SDIC, its membership was drawn broadly - two IUPAC Officers, two Elected Members of the Bureau, one Standing Committee chairman, two Presidents-elect of Divisions, and three outstanding chemists not currently in IUPAC posts but who are familiar with the Union's activities. President Fischli accordingly appointed the following members:

Prof. Joshua Jortner (chairman)

Dr Edwin D. Becker

Prof. Heindirk tom Dieck

Prof. Mostafa El-Sayed

Prof. Robert Gilbert

Dr Alan Hayes

Prof. Upendra K. Pandit

Prof. Pieter Steyn

Prof. Leiv K. Sydnes

Prof. Andrea Vasella

Dr John W. Jost (staff support)

A secondary, but important, consideration was geographic diversity. The SDIC members come from North America, the Asia-Pacific area, the Middle East, Africa and Europe. Appendix 1 gives institutional affiliation and IUPAC office (if applicable) for each member of the SDIC.

\section{Committee Meetings}

The SDIC has held three full-day meetings (24 June 1997; 21 November 1997; and 24 January 1998) and a short meeting at the General Assembly in Geneva (25 August 1997). Participation was excellent. Although not all members could attend every meeting, an average of eight of the 10 members were present at each meeting, and absentees frequently sent written comments in advance. All members contributed actively to the discussions, and a great many ideas were exchanged by e-mail. The findings and recommendations given here represent the result of ideas obtained from many sources, which were subjected to careful analysis and much friendly debate within the Committee.

The SDIC members were quite sensitive to input from many sources outside the Committee. Comments and ideas from the Division Presidents meetings listed above and at the General Assembly in Geneva were important. Views expressed by Bureau and Council members in Geneva and by Commission officers and members during a number of informal meetings provided valuable sources of information. The semi-final draft of the Strategic plan was circulated to the Bureau for comments, and several suggested improvements in wording were subsequently incorporated into the final version.

\section{Strategic plan}

Although all aspects of the Committee's work were dealt with concurrently, the SDIC gave priority to completion of a Strategic Plan for the 1998-99 biennium. The recommended Plan was submitted to the EC and approved by that body on 23 February 1998.

The goals proposed in the VPCA (see Appendix 2), along with papers prepared for the initial SDIC meeting by Profs. Pandit and Steyn (also in Appendix 2), served as the starting point but were modified extensively as a result of discussion by the Committee. The SDIC decided that the Strategic Plan should articulate the scientific policy of the Union in a concise manner that will guide the development of operational plans by the Divisions and other IUPAC bodies. The document should also be valuable in explaining to chemists world-wide and to potential funding organizations just what IUPAC is and what roles it now plays and expects to play in the advancement of the chemical sciences. A preamble provides a short background statement, primarily for use outside the Union.

The Plan itself begins with a brief Mission Statement and is built around a set of long-range goals. The SDIC discussed at length the particular number and statement of the goals and decided that the 10 goals listed seemed to be the smallest number that clearly encompass the broad range of the Union's activities. The first seven goals express IUPAC's commitment to serving the global chemistry community, while the last three describe actions that should be taken to enhance the scope, image and management of the Union itself. Under each goal there are several strategic thrusts. These explain aspects of the goal where necessary and point out specific areas in which IUPAC can realistically develop or continue programs to achieve the goal.

The Plan concludes with a short section on Implementation and Updating. This portion has deliberately been kept brief in recognition of the potentially broad 
distribution of the Plan outside IUPAC. The Secretary General, in consultation with other Officers, will develop and present to the EC a more detailed proposal that discusses the relation between the VPCA and the implementation and updating of the Strategic Plan. It will suggest procedures for soliciting views and approving updates and for assigning responsibilities for implementation of various aspects of the Plan.

The full text of the Strategic Plan for 1998-99 is given on the following pages.

\section{IUPAC Strategic Plan-1998}

The International Union of Pure and Applied Chemistry (IUPAC) was formed in 1919 by chemists from industry and academia. Over nearly eight decades the Union has succeeded in fostering world-wide communications in the chemical sciences and in uniting chemistry-academic, industrial and government-in a common language. IUPAC has long been recognized as the world authority on chemical nomenclature, terminology, standardized methods for measurement, atomic weights and many other critically evaluated data. The Union continues to sponsor major international meetings that range from specialized scientific symposia to CHEMRAWN meetings with societal impact. During the Cold War, IUPAC became an important instrument for maintaining scientific and technical dialogue among the world's chemists.

With the major changes that have occurred worldwide in chemistry and the chemical industry, it is important that IUPAC examine its activities and define its role as the organization principally responsible for promotion of the chemical sciences internationally. Following a series of meetings to obtain input from leaders in chemistry on four continents, IUPAC has redefined its mission and established goals and strategies to guide its approach to the shaping of the chemical sciences and the service of chemistry in a rapidly changing world.

\section{Mission statement}

IUPAC's mission is to advance the world-wide aspects of the chemical sciences* and to contribute to the application of chemistry in the service of Mankind. In so doing, IUPAC promotes the norms, values, standards and ethics of science and advocates the free exchange of scientific information and unimpeded access of scientists to participation in activities related to the chemical sciences.

\footnotetext{
*In recognition of the role of chemistry as a central science in a wide range of fields, the term 'chemical sciences' is used here to refer to chemistry, broadly defined, and to those disciplines and technologies that make significant use of chemistry.
}

\section{Long-range goals}

To further its mission, IUPAC has established a set of long-range Goals and has formulated strategic thrusts that are aimed at achieving each of the Goals. The Goals are summarized here, and the complete set of Goals and Strategic Thrusts for the current biennium is given on the following pages.

1 IUPAC will serve as a scientific, international, nongovernmental body in objectively addressing global issues involving the chemical sciences Where appropriate, IUPAC will represent the interests of chemistry in governmental and non-governmental forums.

2 IUPAC will contribute to the advancement of research in the chemical sciences throughout the world.

3 IUPAC will assist chemistry related industry in its contributions to sustainable development, wealth creation and improvement in the quality of life.

4 IUPAC will facilitate the development of effective channels of communication in the international chemistry community.

5 IUPAC will promote the service of chemistry to society in both developed and developing countries.

6 IUPAC will utilize its global perspective to contribute toward the enhancement of education in chemistry and to advance the public understanding of chemistry and the scientific method.

7 IUPAC will make special efforts to encourage the career development of young chemists.

8 IUPAC will broaden the geographical base of the Union and insure that its human capital is drawn from all segments of the world chemistry community.

9 IUPAC will encourage world-wide dissemination of information about the activities of the Union.

10 IUPAC will assure sound management of its resources to provide maximum value for the funds invested in the Union.

\section{Goals and Strategic Thrusts-1998-1999}

To further its mission, IUPAC has established a set of long-range Goals and has formulated strategic thrusts that are aimed at achieving each of the Goals. These strategies are intended to guide the development of operational plans and the setting of priorities for optimal use of the Union's resources, both human and financial.

1 IUPAC will serve as a scientific, international, nongovernmental body in objectively addressing global issues involving the chemical sciences. Where appropriate, IUPAC will represent the interests of chemistry in governmental and non-governmental forums. 
- IUPAC will conduct projects pertaining to the chemical aspects of important issues of international concern. In addition to projects initiated within IUPAC, input for new projects of scientific and industrial importance may come from international governmental and nongovernmental bodies and from appropriate public groups. Examples are the series of CHEMRAWN conferences, the recent White Book on Chlorine and the studies of methods for disposal of chemical weapons. IUPAC will not undertake projects that cast it in the role of policy development or as an advocate for special interest groups.

- Collaborations with international governmental bodies, such as UNESCO and the World Health Organization, should continue and be strengthened. The IUPAC/UNESCO International Council for Chemistry will serve as the central forum for planning and coordinating work with UNESCO. Collaborations with other individual scientific Unions, with international scientific societies, and with the International Council of Scientific Unions (ICSU) should be enhanced to plan and carry out projects of an interdisciplinary nature.

2 IUPAC will contribute to the advancement of research in the chemical sciences throughout the world.

- The importance of standardized nomenclature, symbols, terminology and methodology is critical to communication in the chemical sciences. To remain the recognized international authority in this area, IUPAC must ensure that important problems are recognized and treated fairly and expeditiously. Collaborations with national and regional chemistry societies, with governmental bodies and with commercial information organizations should be augmented. Greater efforts should be made to encourage adoption of IUPAC recommendations through contacts with authors, editors and publishers.

- The biennial IUPAC Congress is intended to present the most outstanding relevant developments in modern chemistry and to inspire high research standards. Future Congresses should adhere to this principle.

- An assessment should be made of IUPAC sponsorship of specialized symposia in order to strengthen this well accepted program. New significant research fields in chemistry should be highlighted by the initiation of relevant high quality symposia.

- Special attention should be devoted to improving the quality of the Union's scientific publication program. Bibliometric analysis and other criteria can be used to assess the impact of IUPAC books and the journal Pure and Applied Chemistry. IUPAC should take advantage of advances in electronic publishing methods to ensure high quality publications that are disseminated in a rapid and cost-effective manner.

- Policies should be developed for IUPAC's role in the preparation and dissemination of critically evaluated databases, from atomic weights to thermodynamic and other chemical data.

3 IUPAC will assist chemistry related industry in its contributions to sustainable development, wealth creation and improvement in the quality of life.

- IUPAC is unique among the International Scientific Unions in including within its scope a large industrial base. IUPAC is often perceived as being oriented primarily toward academic institutions, but industry benefits equally from much of the Union's work in standardized symbols, nomenclature and terminology, as well as from critically evaluated data. Greater efforts should be made to demonstrate the ways in which IUPAC serves industrial needs directly and indirectly. In addition to the present links provided by the Committee on Chemistry and Industry, serious efforts are needed to engage leaders in the chemical industry and national and international industry associations in dialogue to explore ways in which IUPAC and industry can enhance mutually beneficial interactions.

- IUPAC should be particularly alert to projects that help develop the scientific basis for practices and procedures that protect society while encouraging responsible and sustainable development. Such projects may be initiated in the basic chemistry Divisions, as well as in the mission-oriented Divisions [Chemistry and the Environment, and Chemistry and Human Health].

4 IUPAC will facilitate the development of effective channels of communication in the international chemistry community.

- The vast potential of the Internet should be utilized to enhance information transfer between IUPAC and chemists in many countries. The Affiliate Member Program already provides a base, which should be expanded many-fold.

- Chemistry International should be developed as a forum for highlighting important problems and advances in chemistry and for discussion of science policy and global issues in chemistry.

- Increased efforts should be made to provide information on IUPAC activities and news about important matters of international chemistry to major scientific journals and national and regional chemistry news magazines, which routinely reach hundreds of thousands of chemists world-wide. Feedback should be encouraged.

5 IUPAC will promote the service of chemistry to society in both developed and developing countries. 
- CHEMRAWN Conferences have long provided the principal mechanism for IUPAC to address issues that transcend pure science and have important socio-political aspects. Such Conferences should continue to be promoted, along with follow-up Future Action Programs.

- IUPAC bodies should continue to be alert to projects on matters of societal importance (e.g. chemical weapons disposal, environmental cleanup, biodiversity) that depend heavily on chemical sciences and technology.

- Within its limited funds, IUPAC should consider ways to foster chemistry in developing countries. In many instances, IUPAC's initiative and scientific expertise has been paired with outside funding sources (e.g. recent UNESCO-supported work in the least developed countries and the UNESCO/ UNIDO/IUPAC program in chemical safety) to produce valuable results, and this model should be further elaborated.

6 IUPAC will utilize its global perspective to contribute toward the enhancement of education in chemistry and to advance the public understanding of chemistry and the scientific method.

- Scientists everywhere recognize the critical role played by formal and informal education at all levels, from kindergarten through graduate school, not only for future scientists but also for the general public. The problems associated with such educational programs are enormous. Educational systems, administration and curricula vary drastically by country, locality and individual school and teacher. IUPAC cannot hope to make an impact on detailed curricula or outreach activities in individual countries and localities, but it may be able to complement the efforts of national chemical societies and to coordinate exchange of information. IUPAC should examine carefully what long-range role it can realistically play in international science education and develop appropriate policies. Meanwhile, a number of specific activities can usefully be initiated or continued, as described below.

- The Committee on Teaching of Chemistry (CTC) has been effective in carrying out its program on exchange of information on teaching methods, equipment, etc. CTC should continue to serve as the focal point for IUPAC's programs in this area, but its programs should be broadened. In addition, IUPAC Divisions should be invited to develop complementary projects to enhance education at all levels and to coordinate them with CTC.

- IUPAC should cooperate in whatever ways are feasible with the major new program established by ICSU on Capacity Building in Science, which will endeavor to disseminate information on science teaching in primary schools and science education for the public.
7 IUPAC will make special efforts to encourage the career development of young chemists.

- It is apparent that the future development of the chemical sciences lies largely in the hands of the younger generation of scientists, who often encounter severe obstacles in an era of constrained resources. IUPAC should develop programs that are perceived by 'younger chemists' to be helpful to them and feasible for the Union to undertake within its resources. Young chemists from developing countries who return after advanced training elsewhere may benefit particularly from these programs and from exchange of information with IUPAC via the Internet.

- IUPAC should strongly encourage organizers of the IUPAC Congress and IUPAC-sponsored symposia to provide travel support for younger scientists and to include younger scientists among the invited lecturers.

- IUPAC Commissions and other bodies should make special efforts to recruit well qualified younger scientists for their projects. Several National Adhering Organizations (NAOs) now provide travel support for younger scientists to attend the General Assembly as Associate Members, National Representatives or Observers; other NAOs should be encouraged to follow this lead.

8 IUPAC will broaden the geographical base of the Union and insure that its human capital is drawn from all segments of the world chemistry community.

- The Union is taking active steps toward globalization of its activities with regional meetings and solicitation of input from the world's chemists.

- The 42 National Adhering Organizations and 14 Observer Organizations that currently comprise IUPAC are broadly distributed throughout the world, but there are several geographic regions with little or no representation in the Union and a number of countries with substantial academic and industrial developments in chemistry that do not adhere to the Union. IUPAC should encourage such countries to apply for membership. In addition, IUPAC should stimulate less developed countries to seek Observer status.

- The Union has long had a formal policy of 'fair geographical representation' among Elected Members of the Bureau and informally strives to obtain geographic diversity among IUPAC and Division Officers. While maintaining the focus on expertise, IUPAC's scientific bodies should make efforts to recruit younger chemists, women chemists and chemists from recently developed regions, including in some instances countries that are not yet full Members of the Union.

9 IUPAC will encourage world-wide dissemination of information about the activities of the Union. 
- Much of the valuable work done by IUPAC bodies is published only in Pure and Applied Chemistry or in specialized books and journals. Although such formal and archival publication is essential, greater efforts should be made by individual IUPAC bodies, the Secretariat and the NAOs to disseminate this information as early and as widely as possible to the relevant scientific community. In many instances, high quality reports from symposia, workshops and Commission activities should be prepared not only as formal scientific publications but also as semi-popular documents emphasizing applications. For topics that warrant attention in the popular scientific press, carefully drawn news releases are needed.

- Contacts with major national chemical societies, regional chemistry federations, industrial associations, and government/industry/university consortia should be expanded to ensure that these organizations are fully aware of IUPAC activities and can provide credit to the Union where its activities complement theirs.

- Improved two-way communication with NAOs concerning science policy, planning and implementation of projects and other activities is needed. Special efforts should be made to prepare suitable material describing IUPAC programs and accomplishments in a form that will assist NAOs in recruiting Company Associates.

10 IUPAC will assure sound management of its resources to provide maximum value for the funds invested in the Union.

- The Union can undertake its many activities only because of stable financial support from its National Adhering Organizations, which in turn usually obtain their resources from government and/or industrial sources. IUPAC has a continuing responsibility to demonstrate to its sponsors that all relevant management tools, including the use of modern information technology, are employed to maximize productivity in the administration of the Union.

- IUPAC should encourage philanthropic donations to the Union's endowment. With continued wise investment strategies that assure maximum return consistent with reasonable safety, the endowment and operating reserves will provide a continuing source of funding that augments and leverages the subscriptions from the NAOs.

- Although the purpose of the IUPAC publications program is the dissemination of scientific information, this program has for a number of years provided substantial income to help support IUPAC's other work. As the program is redirected in the era of electronic publishing, efforts should be made to continue to have publications as a source of funds, rather than a drain on the Union's resources.
- Officers of IUPAC bodies and the Secretariat should continue to be alert to possible sources of funds for specific projects from outside groups (e.g. UNESCO, ICSU, charitable foundations and industry) to augment the base funds provided by NAO subscriptions.

\section{Implementation and updating of the Strategic Plan}

The Strategic Plan is intended to articulate the scientific and operational policy of IUPAC, providing overall policy guidance to the IUPAC Divisions and Standing Committees for assistance in the development of coordinated programs to advance the Union's mission. This Plan should not impede or replace initiatives at all levels within the Union. The Council, Bureau and Executive Committee will formulate procedures for ensuring that operational programs will be drafted and resources allocated within the context of the Strategic Plan, that responsibilities will be assigned for implementation of programs, and that outcomes will be evaluated.

Each biennium the strategic thrusts will be analyzed and updated as needed. The long-range goals may also be revised when appropriate, but probably on a longer time frame.

\section{Organization and management of scien- tific work}

Most of the Union's core scientific programs have been built around the work carried out in its seven Divisions and a large number of Commissions (currently numbering 37), with support from the Standing Committees and several Divisional subcommittees. With limited financial resources from IUPAC, principally to defray costs of travel and administrative expenses, and far larger inkind support from their employers, the members of these IUPAC bodies voluntarily devote enormous amounts of time to advancing chemistry. Their accomplishments in obtaining international agreement on nomenclature, symbols, terminology and methodology have produced a world-wide language of chemistry. Many of these groups continue to establish values for critically evaluated chemical data, from precise atomic weights to thermodynamic properties, while others provide physical and chemical characterization of various substances. Some IUPAC bodies are concerned with criteria for training and education in specific branches of chemistry, and many bodies traditionally organize high quality international symposia in a wide range of chemical fields.

In spite of the widely acclaimed past accomplishments of the Union and its continuing successes in very many areas, increasing concern has been expressed by the world-wide chemistry community and by several of 
IUPAC's National Adhering Organizations (NAOs) as to the overall impact of the Union's programs on contemporary problems in chemistry. Over the last decade there has been much introspective evaluation of the Union's scientific work, frequent calls to modify the structure of the Divisions and Commissions, and imposition of a large number of requirements designed to assure that only projects of high quality and high priority are undertaken. The results of these efforts have been largely disappointing in that they have resulted in little change in the organization and management of the Union's work. Moreover, these continuing efforts to change first one, then another IUPAC body have proved frustrating and sometimes demeaning to many of the dedicated individuals who voluntarily carry out this work.

Following detailed discussions among the IUPAC Officers and the Division Presidents and Vice-Presidents during 1996-97, the Secretary General presented an analysis of the problems and made recommendations for major changes in both organization and management of the scientific activities of the Union. The Secretary General's Report [SGR] was presented to the Executive Committee in April 1997 and after considerable discussion the basic concepts were accepted and the SDIC was assigned the task of assessing the feasibility of specific proposals and recommending in detail how the desired changes could be accomplished. The full SGR is given in Appendix 3. The Report has been widely disseminated within IUPAC bodies and among the Union's NAOs, and many comments on the Report have been provided to the SDIC to help guide its work and recommendations.

The SDIC's analysis of the present organization and of the means by which its projects are initiated and managed has highlighted a number of factors that are of concern, as follows:

- Responsibility for initiation, development and management of IUPAC's projects is divided among seven Division Committees and 37 Commissions.

- Largely because of this highly decentralized structure and resulting fragmentation of areas of responsibility, it has frequently proved difficult, time-consuming and sometimes impossible to develop interdisciplinary projects in spite of the acknowledged importance of such projects to the future of chemistry and to the future of IUPAC.

- About half of the Union's limited financial resources are devoted to supporting the Commissions, with no clear relation between resource utilization and specific projects. Although individual expenditures are quite modest, collectively the sums are significant. A large fraction of the approximately $\$ 525000$ cost of a typical General Assembly pays for travel and subsistence of Titular Members, and much of the Divisions' collective biennial budgets of about $\$ 420000$ is devoted to meetings of Commissions in the years between General Assemblies.

- There has been a proliferation of projects (numbering more than 400 in the last biennium) of varying quality and urgency, often approved routinely without stringent outside review. There is little incentive to limit the number of projects or give serious consideration to priorities since there is virtually no relation between the importance of a project and the (often meager) financial resources allocated to it.

- Ideas for projects usually arise within Commissions, sometimes because the Commission has established a clear international need, at other times simply because an individual Member is interested in the subject and willing to devote time to pursuing the project. Overall, there has been relatively little formal effort to solicit views from NAOs, chemical societies and the world-wide chemistry community. Refereeing of proposed projects outside IUPAC has been spotty, and retrospective evaluation has been uneven.

- Although the Secretariat has, over the years, done an excellent job of providing administrative and logistical services to all IUPAC bodies, it has not been staffed to provide professional help to groups carrying out scientific projects. Even very modest professional staff assistance could be valuable in developing projects and in insuring their timely completion.

- The process by which Members of Commissions and Division Committees are selected has long given rise outside the Union to the view expressed in 1979 that IUPAC is a 'charmed circle'. Although the Union has made efforts to limit the length of terms in order to allow more people to participate, the procedure by which Members elect their own successors with no formal outside input strengthens the perception of an inward-looking organization.

The Secretary General's Report addressed many of these perceived deficiencies and advocated the conversion of most of the Union's scientific activities 'from a primarily static Commission structure to one that is largely based on time-limited Commissions formed to carry out specific, well defined tasks.' The Executive Committee approved this concept but recognized that many details needed to be examined. The SDIC was asked [Tasks 3 and 4] to determine whether such a radical change in IUPAC operations would be feasible and if so to provide specific recommendations on how to achieve this objective.

The SDIC concludes that it will be feasible to reorient much of the Union's scientific work to a project-driven system carried out by short-term Task Groups that report to Division Committees, with much less emphasis 
on long-term Commissions. However, implementation will require adoption of an integrated program, as described below. The time frame for implementation has been carefully thought out in order to move the Union forward as rapidly as possible but to allow adequate time for completion of existing projects and for phased conversion from the present Division/Commission structure to one that is more dynamic.

\section{Responsibilities of Division Committees}

One key element of the SDIC proposal is the consolidation within the Division Committees of the responsibility for organization and management of both continuing programs (such as symposia) and short-term projects. These Committees and their Officers will provide the scientific leadership of the Union. They must be carefully chosen to ensure that each Committee has the necessary vision, breadth and expertise to seek out promising areas for IUPAC involvement, to select the highest quality proposals and to manage the implementation of projects.

Bylaw 4.1 (see Appendix 4) describes the role of Division Committees in some detail, largely in terms of structure and process (membership and size, elections, limitations of authority, reports, Committee meetings, etc.). The functions of the Division Committee emphasize its administrative role in forming and dissolving Commissions and as an intermediary between Commissions and the Bureau. However, the Bylaws provide broad (if somewhat nebulous) authority to the Division Committee 'to plan and organize scientific meetings and other activities...' and 'to prepare a budget for the Division...' The SDIC proposes that the Bureau promulgate a policy that builds on the statutory framework and makes it clear that the Division Committee is to be the focus of scientific work in the Division and has the overall responsibility itself for initiating, developing and managing the work of the Division.

As described below, the Division Committee will be expected to select scientific Task Groups to carry out individual projects and may appoint advisory groups as needed. Although the proposed policy is formulated in terms of each Division Committee individually, the SDIC believes that interdisciplinary activities will be of increasing importance; hence, each Division Committee must be charged with making positive efforts to initiate interdisciplinary projects and to work collegially with other Division Committees to provide effective development and management of such projects.

\section{Election of Division Committees and Division Officers}

Bylaw 4.1 specifies that the Division Committee is to be elected by all Members of the Division (Titular and Associate), i.e. the members of all Commissions in that Division plus members of the existing Division Committee. With long-range changes in Commission structure as proposed below, it may eventually be necessary to change the election process, but the SDIC believes that the procedure in the Bylaws need not be altered at present. Bylaw 4.1 provides no guidance on nomination of candidates for Committee Members and Officers, but rather leaves this aspect entirely up to each Division. Here the SDIC believes that specific criteria and procedures are essential to ensure the nomination of candidates who will provide the necessary scientific leadership, breadth of expertise and management skills required of the revitalized Division Committee.

The SDIC recommends that the Bureau be asked in September 1998 to adopt uniform nomination policies and procedures for all Divisions, as given below, to be effective immediately and thus govern the 1999 election process. The Bureau should also formally give Divisions authority to suspend the application of all Division Rules that are in conflict with the Bylaws [as several are now] or with the new policy enunciated by the Bureau. After some experience is gained, the Bylaws and Division Rules should be suitably revised, but that could better wait until later years.

The policy should state the intention of insuring that the Committee will seek members from as broad a segment of the world-wide chemistry community as is consistent with the charge to the Division. The Bylaws already recognize the need to renew the Committee's membership by limiting terms to four years for non-Officers. With the procedures given below, this limitation should ensure that there is a broadly based Committee with a healthy turnover in membership. The Bylaws provide that Officers may serve for an additional 4-6 years, a provision that allows flexibility to provide adequate continuity and experience.

\section{Nominating Committee}

The SDIC recommends that each Division President/ Division Committee appoint a nominating committee of five members unless the Bureau or EC agrees to an exception. The nominating committee should consist of no more than two current members of the Division Committee and three others chosen for the breadth of their expertise. While two of these three should come from outside IUPAC, it may be desirable in some instances for one member to be from another IUPAC Division. The overall membership should be approved by the EC. Af- 
ter consultation with the Division Presidents, the Bureau should establish a timetable for making nominations, including sufficient time to permit the nominating committee to solicit suggestions from inside and outside the Division.

\section{Nominees for Division Committee}

The nominees should be widely known and respected scientists from academia, government and industry. If feasible, a journal editor should be included among the nominees. The aim should be to create and maintain a Committee that has scientific stature and breadth. Within these guidelines, each Division and its nominating committee should have considerable flexibility to meet the specific needs for each election --for example, to designate categories of vacancies if desired to ensure diversity in subject matter, geographic distribution, or other characteristics. More than one nominee for each vacancy is desirable but should not always be required. The President of IUPAC should review the list of nominees prior to the election to ensure that the Bureau policy has been followed.

\section{Size of Division Committees}

The size of the Division Committee is set by the Bylaws as 10 Titular Members (TMs) unless otherwise specified by the Bureau, plus up to six Associate Members (AMs). At present, the Committees range from seven to nine TMs [except for the Division of Chemistry and Human Health $(\mathrm{DCHH})$, where the Sectional structure adds complexity]. If the Division Committee is expected to be broadly based, 10 TMs seems reasonable as a general rule. However, some Division Presidents spoke very favorably at Geneva about improving the science orientation of the Committee by having the Commission chairmen become part of the Committee. As an interim step toward establishing new Division Committees, a Division might propose that an existing Committee be expanded temporarily in this way. The Bureau should provide flexibility and, on a case-by-case basis, allow the maximum size for each Division Committee to exceed $10 \mathrm{TMs} / 6$ AMs for a specified period.

\section{Division Officers}

The Bylaws state that the Division Committee shall elect its Officers from among the current and incoming Committee TMs. The elections are subject to approval by Council, but this retrospective approval is virtually automatic. The SDIC recommends that, following discussion with the Division Presidents, the Bureau specify a uniform procedure to insure that the nomination of one or more candidates for each Division office is conducted in a thoughtful way, with adequate consultation within the
Committee and with the President of IUPAC. Each Division Committee should choose its own leaders, but the SDIC believes that appropriate advance consultation will strengthen the mandate of the elected Division Officers.

There is currently some variation among the Divisions in the length of the term for each Officer and the practice of succession through different offices. The SDIC does not believe that there is necessarily one 'best' policy, but the Division Presidents should discuss the alternatives and initiate change where desirable. It has been pointed out that some high calibre, busy chemists might be more willing to serve if the period of service is not excessive.

The Bureau and Executive Committee should give special attention to the application of the above recommendations within the current Sectional structure of the Division of Chemistry and Human Health. The SDIC does not believe that it is within the Committee's mandate to make specific recommendations for this unique situation.

\section{Project-driven system}

The proposal in the SGR to convert the bulk of IUPAC'S scientific work to a project-funded system with primarily time-limited commissions has elicited considerable discussion at all levels within IUPAC. The Division Presidents who have expressed opinions seem to be completely in favor of a project-funded system, and a number of individuals from Commissions also have given a positive response to this concept. In fact, many Commissions already carry out individual projects with short-term Working Groups, usually composed partly or entirely of Commission members, and in some instances modest funds are allocated to specific projects.

The second part of the proposal, 'time-limited commissions,' and its corollary of giving up 'permanent' commissions has elicited considerable concern from most Commission members. The SDIC is well aware of and sensitive to these concerns. Abolishing a single Commission might appear to be tantamount to saying that the sub-field covered by that Commission is of little importance. Moreover, there are questions as to how suitable projects could be generated without a Commission devoted to a particular subject area.

\section{Current status of Commissions}

The existence of a more or less permanent Commission in a particular subject area has many virtues: There is a cadre of chemists who have accepted responsibility to think about that area and to develop ideas for useful IUPAC projects. The awarding of the title 'Titular Member' or 'Associate Member' of a Commission often pro- 
vides sufficient prestige to enable the individual to obtain his/her employer's approval to devote time to IUPAC work-an important consideration in a company or government laboratory but not generally in academia. Also, the 'Member' designation often permits an individual to obtain financial resources for travel and administrative costs-important in all employment sectors, especially for Associate Members. In addition, the existence of a permanent Commission provides an opportunity for appointment of National Representatives-an important consideration for many NAOs in bringing forward some of their better chemists who might not be widely known.

The SDIC believes that the principal shortcomings of the present system of 'permanent' Commissions are (i) perpetuation of the Commission's membership by selfselection, with only nominal approval at higher levels; (ii) generation of projects largely within a Commission in accord with the interests of its members; and (iii) allocation of a large fraction of IUPAC's budget to maintenance of the Commissions and provision for their meetings, irrespective of the quality, quantity and timeliness of the work carried out by the Commission.

\section{Proposed funding for Commissions}

These problems disappear if there are only time-limited Commissions to carry out specific projects, where the project is defined and the Commission membership is chosen by someone or some group outside the Commission. The question addressed by the SDIC was: How can IUPAC best accomplish these goals and yet retain some or all of the advantages listed above for 'permanent' Commissions? The SDIC believes that the answer is to have projects carried out by short-term Task Groups reporting to the Division Committee, while permitting a limited number of Commissions to be formed, under strict conditions, as advisory groups that would meet only as needed.

One key aspect in effecting such a change is to break the link between Titular Membership and financial support. This could be accomplished most cleanly by a repeal or modification of Bylaw 4.307:

Titular Members of Commissions have the right to receive contributions towards travel and subsistence expenses from funds of the Union as authorized by the Treasurer acting on behalf of the Union. Contributions may be made to Associate Members or members of subcommittees on recommendation of the Division or Section President and with the agreement of the Treasurer.

Removing the 'right' to receive contributions changes an entitlement to a discretionary expenditure that is related to the need for particular travel. Rather than having each of its Commissions meet at every General Assembly, a Division Committee could authorize meet- ings and travel only when necessary. This change in policy would leave permanent Commissions in essentially an advisory role unless some or all members were actively engaged in one or more projects for which funding has been approved. However, such an advisory role can be very important in developing new projects. With modern communications technology, much can be accomplished, even without regular meetings.

\section{Formation and Termination of Commissions}

Withdrawal of automatic funding for TMs would not solve the problem of having in perpetuity 37 Commissions on subjects that might not be optimal, even for advisory groups. Experience has shown that it is virtually impossible to terminate a single Commission unless there is almost unanimous agreement among all members of the Commission. The SGR [Appendix 3] gives illustrations dating back to 1955 of efforts by IUPAC Presidents to terminate permanent Commissions. However, Council can be asked to exercise its authority under Bylaw 4.302 [see Appendix 4] not to approve the extension of any current Commission beyond 2001. The SDIC believes that it will be less divisive to the Union and more acceptable to each Commission to have all Commissions formally terminated than to try to terminate some and leave others.

Under this plan, Division Committees would examine their needs during the period 1999-2001 and request the Bureau and Council to form new Commissions as needed. These could be long-term (but with a specified term-no more than 8-10 years) to provide continuing attention to a field or to organize or manage a continuing activity, such as a series of symposia. In some instances they could be short-term (2-4 years) to accomplish a specific task for which the prestige of a Commission, not just a Task Group, is needed. For each proposed Commission, the Division Committee would have to make a persuasive case and follow the procedures given in Bylaw 4.301 [see Appendix 4]. To prevent a recurrence of the present situation with a large number of long-term Commissions, the Bureau should go beyond the requirement in Bylaw 4.301 for 'an indication as to the probable duration of the life of the new body' by specifying a lifetime and thus ensuring the automatic termination of the Commission unless positive action is taken to extend its life. The SDIC believes that this can be done at present on the basis of Bureau policy but that eventually Bylaw 4.301 should be modified.

\section{National Representatives}

National Representatives (NRs) play an important role in increasing the geographic breadth of IUPAC bodies and permitting the close involvement of individual NAOs 
with IUPAC work. Bylaw 4.305 [Appendix 4] defines the participation of NRs in Commissions, and there are many active NRs. Although there is no statutory underpinning, two of the seven Division Committees and several Standing Committees also have NRs.

Under the new structure proposed here, NRs can still participate in any Commissions that are formed, but opportunities may be limited. There should be provision for direct links of NRs to all Division Committees, which will become the centers of scientific activity. Such NRs could provide extremely valuable links to NAOs and thus facilitate the generation of ideas for projects and suggestions for individuals to serve on Task Groups. The SDIC recommends that the Bureau, after consultation with Division Presidents, establish a policy for appointment of National Representatives to Division Committees as non-voting members, and for participation of NRs in the work of the Divisions' Task Groups.

\section{Conversion to a new project-driven sys- tem}

The SDIC recommends that the Bureau approve and implement a policy of relying on short-term Task Groups to carry out specific projects under the direction of Division Committees. A limited number of long-term Commissions could be formed to advise each Division Committee and augment its breadth of expertise. Three concurrent actions are required, as follows:

1 In September, 1998, the Bureau should approve a policy of providing IUPAC funds for support of approved projects and other specific activities, not support of Titular Members per se. The Bureau should endorse repeal or amendment of Bylaw 4.307, and Council should be asked to take this action in 1999, to be effective January 1, 2002.

2 In September 1998, the Bureau should endorse the phasing out of all existing Commissions by the end of 2001 and to recommend that Council take this action at the General Assembly in 1999. The Bureau should indicate that it will be receptive to very well justified proposals from Divisions to form a small number of new long-term Commissions, each with a termination date of no more than 10 years, to carry out activities that require such a long-term commitment.

3 The Divisions should be encouraged by the Bureau to accelerate the timetable in (1) and (2) to the extent feasible. Since all appointments to Commissions are now made for a two-year period, it may be desirable for a Division, on a case by case basis, to reduce the size of particular Commissions and to divert the financial resources to support of specific projects. The Treasurer should be asked to cooperate with Divisions in redirecting financial resources, includ- ing funds reserved for the General Assembly, away from support of TMs per se toward support of individuals working on projects. Beginning in 2002, major changes in Division budgets will occur, as described in a later section.

\section{Operation of a project-driven system}

One of the principal concerns about the conversion of the Union's scientific activities from a Commissionbased system to one based on individual projects is the lack of a very large permanent structure that can initiate and develop suitable projects. This is a valid concern, as pointed out in the SGR and confirmed by many comments from Commission members. The SDIC believes that the problems can be overcome as discussed below. There are three aspects that must be considered-(i) ideas for new projects, (ii) personnel interested in and capable of carrying out the project, (iii) development of the project in detail and management of the project.

\section{Sources of ideas}

Under the current system, ideas for projects are largely generated within an individual Commission. The ideas come from one or more individuals who are expert in a particular field and who have thought about the problems that give rise to a project. In some instances there may be a widely perceived need within the relevant scientific community for IUPAC action. At the other extreme, there may be a single individual who thinks that IUPAC could make a useful contribution to a particular problem or discipline. The SDIC believes that under the proposed structure these and other sources can be tapped for ideas.

Division Committees are to be given the principal responsibility for developing projects. To some extent, projects should emerge from discussions within the Committee, augmented initially by the chairmen and members of current Commissions as long as those Commissions exist. Division Committees should solicit views on potential projects from participants at relevant IUPAC symposia and other specialized meetings. This will require some planning and organization to arrange suitable feedback, perhaps by designating one or more Committee members to attend suitable meetings. The Secretariat may eventually be able to provide a professional staff member to assist, but the extent of the Secretariat's role needs to be worked out.

Ideas for projects should be actively solicited from NAOs, national chemical societies, regional federations, international specialty societies (primarily IUPAC Associated Organizations), and IUPAC Fellows. Simply sending out a call for projects is unlikely to be successful, as indicated by the general lack of response to simi- 
lar invitations for Pool Projects over the last six years. A continuing effort from Division Committees is needed, with carefully planned follow-up action by the Secretariat. Moreover, vague ideas for potential projects are not sufficient. There must be adequate development of the concept, evaluation of its feasibility for IUPAC and realistic cost estimates. The Division Committees are ultimately responsible for most of this work, but considerable help from the Secretariat will be required.

IUPAC should continue to sponsor various levels of projects. Some may be of sufficient importance and urgency that significant resources should be committed, while others may be more along the lines of many current projects-often initiated by one or a few people, who are prepared to do all the work with little IUPAC support. In fact, in some instances the formal endorsement by IUPAC may be sufficient to attract other local sources of funds for individuals. However, each project should pass quality checks, as discussed below, and responsibility for conduct of each project should clearly be vested in an individual or a well defined Task Group.

\section{Personnel to carry out projects}

In some instances the current procedure by which the proponent of a project is usually charged with pursuing it may be sufficient and desirable. In other instances someone or some organization may make a compelling argument that IUPAC should undertake a project but with no suggestion as to who would be both capable and willing to carry out the volunteer work. The relevant Division Committee, with the active assistance of the Secretariat, must be able to identify suitable individuals with requisite expertise. Databases provided by journal editors and NAOs and developed from sources such as citation indices will undoubtedly prove to be valuable. Use of electronic communication tools, especially the Internet, should be beneficial.

Another aspect that deserves some guidelines is the geographic representation on a particular task group. For the current Commissions, the paramount requirement is expertise in the field, but considerable efforts are made to insure reasonable geographic balance. The SDIC believes that each Task Group should be treated on its own merits. For some projects it may be desirable to have the Task Group rather localized in order to prepare a document quickly and at minimum cost. In such cases, there should be a geographically broad review of the initial document and ultimate stamp of approval by a group viewed as representative (perhaps a Commission or the Division Committee). For other projects, it may be politically important at the beginning to have a Task Group balanced in several ways, including geography. In any event, there should be guidelines to insure that capable chemists from 'distant' places are included as appropriate.

\section{Project development and management}

The SDIC envisions that projects will be developed by the relevant Division Committee and that the Task Groups responsible for projects will report directly to that Committee. The elimination of the extra level of management currently supplied by a Commission is a key advantage of our proposal. However, the Division Committee must recognize the increased responsibilities and be prepared to accept them. The members of the Committee, individually and collectively, should be expected to provide active support to the Division President. The SDIC believes that the Secretariat must be able to offer substantial assistance to Division Committees and Officers in recruiting individuals to work on some projects, and the Secretariat must assist in the management of projects. The SDIC recognizes that these responsibilities will require an enhancement of the professional staff of the Secretariat but does not believe that the essentially volunteer character of IUPAC should change. Likewise, the traditional size and budget of the Secretariat need not increase if the staff at the new site is developed to provide professional assistance, in addition to administrative support.

\section{Evaluation of projects}

Current policies require that proposed projects be subject to 'outside evaluation' before approval by a Commission and by the Division President. In some instances rigorous critiques are obtained, analogous to those given by a referee of a journal article, while in other instances only a cursory analysis is undertaken. Past practice has often limited the description of a new project to a short paragraph, which is often inadequate for critical review by someone outside IUPAC. Since the 'priority' accorded a project has little or no relation to funding, there has been little incentive to improve either the project description or the rigor of evaluation.

The SDIC believes that a system for evaluating proposals prior to approval is essential. It must be seen within IUPAC as fair and must be viewed outside IUPAC as rigorous. Moreover, at some time after completion of a project there should be systematic evaluation of the accomplishments.

\section{Prospective evaluation}

A prospective evaluation has two purposes. First, it should weed out any proposal that IUPAC does not want to endorse-for example, something that is irrelevant to IUPAC's mission; that might be embarrassing to the Union; or that might be widely perceived as being undertaken solely to give credibility to an individual's 'pet project'. Although there may be few such projects proposed, it is important to the Union's reputation that 
the review system impose some check point for such eventualities.

The second purpose of prospective evaluation is to allocate the Union's resources in an optimum way. In setting up procedures, IUPAC should be careful not to impose burdensome requirements. There should be considerable flexibility tied to the level of resources required. For example, an essentially one-person project (the product of which would ultimately be reviewed and approved broadly) might make few demands on IUPAC resources and require relatively little justification. A project that is funded within a Division's budget must be justified there but not at higher levels. A project that is proposed for central funding (the successor to 'pool projects') should have adequate justification for this purpose. A project that requires outside resources (UNESCO, ICSU, industry, etc.) may require more detailed justification. For all types of projects the totality of IUPAC resources should be considered, including Secretariat support and publication requirements, as well as direct costs for the project. It is likely that the principal direct costs will continue to be for travel and subsistence; however, even with the voluntary contribution of time by Task Group members there may be instances where modest expenditures for specific purposes, such as data evaluation or purchase of reagents, might be warranted.

The Bureau should develop general criteria to guide reviewers and establish detailed procedures for prospective evaluation at the Division level and centrally. The SDIC believes that the criteria should include the following:

- Inherent scientific quality of the project

- Anticipated impact on some aspect of the chemical sciences or interdisciplinary activities

- Relation to IUPAC's goals and strategic thrusts

- Provision for publication of results and widespread dissemination

- Cost/benefit ratio

\section{Retrospective evaluation}

Retrospective review and evaluation of individual projects has generally not been done at the IUPAC level, but some Commissions or Divisions do look at outcomes in a serious way. The SDIC believes that the Bureau should set criteria for either a central evaluation or a mandated Division evaluation of the impact of a project and of the outcome relative to what was anticipated. The nature and time frame for such an evaluation must be decided on a case by case basis, but must involve consultation widely with the relevant scientific community. Where applicable, quantitative assessments, such as literature citations or adoption of nomen- clature by major journals, should be employed. Over a period of years, such retrospective evaluations can provide useful guidance on the selection of future projects. In addition, the retrospective review may be valuable in identifying material that can be used for public relations purposes and for future fund-raising.

\section{Role of the Secretariat}

Successful implementation of most of the recommendations by the SDIC will require more active assistance by the Secretariat in the management of Divisional activities than has been true in the past. The Secretariat must provide staff support to Task Groups, particularly those conducting projects with an urgent completion date. This support need not consume a large amount of time for any individual project but can be of critical importance in providing to a Task Group of volunteers the management discipline that can come only from fulltime paid staff.

Collectively, for the projects within all Divisions' programs, this responsibility will consume significant staff time. Fortunately, this additional obligation is consistent with the Executive Director's desire to change the emphasis of the Secretariat's duties by utilizing computer and electronic communication technologies to minimize staff time and costs in carrying out administrative aspects of the work. The staff resources thus freed can be used for more professional activities, including assistance to the Divisions. In addition, the Secretariat should over time acquire information on potential sources of funds from industry and from international governmental and non-governmental organizations that might be available to help support certain IUPAC projects.

\section{Financial considerations}

The SDIC is well aware that financial support of the Union through subscriptions by NAOs is likely to expand, at most, by amounts to cover inflationary increases. Our recommendations are aimed at improving the setting of priorities and the management of activities to ensure cost-effective operations of the Union's programs. The Strategic Plan should be viewed as providing a rational approach to dealing with the many aspects of chemistry to which IUPAC can and does contribute, rather than a call to undertake large, new programs. The significant changes recommended in the organization and management of activities within the Divisions will be accomplished within the current budgetary framework.

The large savings that will result from removing support of regular meetings of Commissions will be redistributed, largely to support specific projects, with some funds used to solicit advice and plan projects and others perhaps needed for improved management. The SDIC 
recommends that the Treasurer and Finance Committee analyze the budgetary implications of the SDIC's recommendations and propose to the Bureau a plan for redistributing projected savings in future General Assembly budgets beginning with the 2002-2003 biennium. Provision should be made to provide adequate funds to each Division, while retaining a central pool of funds that can be awarded competitively for interdivisional projects or for projects beyond the scope of an individual Division's resources.

Currently TMs are distributed from a central pool for approved 'pool projects,' with financial support related only to the number of TMs. Under the new policy, the central pool will consist of money, rather than TMs. If these funds are to be used effectively, there must be a mechanism for preparing and reviewing applications and for making decisions in a manner that fully utilizes the scientific expertise of the Division Officers but permits decisions to be made by an impartial body. After consultation with Division Presidents, the IUPAC Officers should propose to the Bureau a mechanism for reviewing applications for project funding and allocation of resources. Guidelines should also be developed for securing outside funding to prevent apparent conflicts of interest and to maintain the Union's independent character.

\section{Summary of recommendations on or- ganization and management of scientific activities}

The SDIC recommends an integrated program, with a defined time frame, to convert from the present Division/ Commission structure to one that is more dynamic and under which approved projects will be carried out by short-term Task Groups that report directly to the Division Committees. Principal features of this proposal are as follows:

\section{A. Division Committee}

1 The Division Committee is to become the focus of scientific work in the Division and has the overall responsibility itself for initiating, developing and managing the work of the Division. The Committee should solicit ideas for projects from NAOs, national chemical societies, regional federations, international specialty societies (primarily IUPAC Associated Organizations), IUPAC Fellows, and participants at relevant IUPAC symposia and other meetings.

2 Division Committees, with the active assistance of the Secretariat, must be able to identify suitable individuals with requisite expertise to carry out projects. Overall, but not necessarily for each project, individuals will be recruited world-wide.
3 The Bureau will develop a system for prospective and retrospective evaluation of projects, with general criteria to guide reviewers.

4 In order to strengthen the role and mandate of Division Committees, the Bureau will establish uniform nomination policies and procedures for the Members and Officers of all Division Committees, to govern the 1999 election process. These procedures will include the following points:

(a) Each Division President will appoint a nominating committee of five members, consisting of no more than two Members of the Division Committee and three others chosen for breadth, with the overall membership approved by the Executive Committee.

(b) Each Division will insure that the nomination of candidates for Division Officers is conducted in a thoughtful way, with adequate consultation within the Committee and with the President of IUPAC.

(c) The Bureau will give Divisions authority to suspend the application of all Division Rules that are in conflict with the Bylaws or with the new policy enunciated by the Bureau. Within existing Statutes and Bylaws, the Bureau will provide maximum flexibility to Divisions in adjusting the size and composition of the Division Committee and Commissions.

5 The Bureau will establish a policy for appointment of National Representatives to Division Committees and for their participation in the work of the Divisions.

6 The Bureau and Executive Committee will give special attention to the application of the above recommendations within the current Sectional structure of the Division of Chemistry and Human Health.

\section{B. Commissions}

7 The Bureau will endorse the termination of all existing Commissions by the end of 2001 and recommend that Council take this action at the General Assembly in 1999. Any new Commissions formed must strictly adhere to the requirements of Bylaw 4.301 and have a definite termination date.

8 The Divisions will be encouraged to accelerate the timetable given above for reduction in Commission size and reallocation of financial resources to support of specific projects. The Treasurer and the Bureau will provide the maximum flexibility in allocation of money and Titular Members.

\section{Secretariat}

9 The Secretariat will provide professional staff assistance to Division Committees and Task Groups to facilitate the development, conduct and management of projects and the recruitment of individuals for Task Groups. 


\section{Funding}

10 The Bureau will approve a policy of providing IUPAC funds for support of approved projects and other specific activities, not support of Titular Members per se. The Bureau will endorse suitable amendment of Bylaw 4.307.

11 The recommended changes are to be implemented within existing budget levels provided by NAO subscriptions (adjusted only for inflation). The large savings that will result from removing support of routine meetings of Commissions will be redistributed among scientific programs to fund specific projects and to finance necessary meetings of reconstituted Commissions and other planning and advisory groups.

12 Budgets will be adjusted to provide adequate funds to each Division and to retain a central pool of funds that can be awarded competitively for interdivisional projects or for projects beyond the scope of an individual Division's resources. The Bureau will establish mechanisms for reviewing applications for project funding and allocation of resources, both within Divisions and centrally.

\section{Summary of formal actions required}

Strategic Plan:

The Executive Committee has approved the Strategic Plan for 1998-99 and has authorized its use to guide program development during the current biennium. The Plan has been distributed widely within IUPAC and among the NAOs, and has been publicized outside the Union. Proposed actions for implementation of the Plan and for updating it biennially will be presented by the IUPAC Officers separately from this report.

Organization and management of scientific activities If the EC accepts the recommendations of the SDIC in April, 1998, implementation will require a series of actions that may be summarized as follows:

April-September 1998: The EC should ensure that the report by the SDIC, together with its own views and proposals for implementation, is widely distributed within IUPAC and among the NAOs with a request for comments, identification of potential problems, and suggestions for improvements. During this period, written communications and informal dialogue among IUPAC Officers, Division Presidents and Commission Officers should be encouraged.

September 1998: The Bureau will be asked to approve a policy that (i) vests in Division Committees responsibility for selection of and management of scientific projects, (ii) defines the composition of Division Committees and procedures for selection of Division Committees and Division Officers, (iii) establishes

criteria for approval of projects, and (iv) calls for a phasing out of all current Commissions.

October 1998: NAOs should be advised of the new policies and asked for comments and/or suggestions for modification of the policies. NAOs should be advised of changes in Bylaws that will be requested in 1999.

October 1998-August 1999: Division Officers and Division Committees, in consultation with their Commission Officers, should develop plans for making the transition to a project-based system no later than 2001, with some aspects phased in if desired in 1999. IUPAC Officers and the Secretariat should provide any required assistance and cooperate in modifying procedures whenever possible to facilitate the Divisions' efforts.

August 1999: Council will be asked to modify Bylaw 4.307 as described in the report. Council will be asked to terminate all existing Commissions, effective $31 \mathrm{De}$ cember 2001.

\section{Concluding statement}

The SDIC recommends that the EC approve this program, request comments from IUPAC bodies and the Union's National Adhering Organizations, and submit the proposal (modified in detail if needed as a result of comments received) to the Bureau for action. The Bureau will be asked to endorse this program in September 1998 and set in motion the steps outlined above.

\section{Appendix 1. Membership of the SDIC}

$\begin{array}{lr}\text { Prof. Joshua Jortner } & \text { Vice-President, 1996-97 } \\ \text { (Chairman) } & \text { President, 1998-99 }\end{array}$

Tel Aviv University

Israel

Dr Edwin D. Becker

Secretary General, 1996-99

National Institutes of Health

USA

Prof. Heindirk tom Dieck

Gesellschaft Deutscher Chemiker

Germany

\section{Prof. Mostafa El-Sayed}

Georgia Institute of Technology

USA

Prof. Robert Gilbert

University of Sydney

Australia

Dr Alan Hayes

ICI (Retired)

UK

Prof. Upendra K. Pandit University of Amsterdam Netherlands
Macromolecular Division: Vice-President, 1996-97 President, 1998-99

Chairman, CHEMRAWN

Committee, 1996-97

Vice-President, 1998-99

Organic Chemistry Division:

Vice-President, 1996-97

President, 1998-99 
Prof. Pieter Steyn

University of Potchefstroom

South Africa

\section{Prof. Leiv K. Sydnes \\ University of Bergen \\ Norway}

Prof. Andrea Vasella

ETH

Switzerland

Dr John W. Jost (staff support) IUPAC Secretariat

\section{Appendix 2. Initially suggested goals and mission statements}

IUPAC goals [from Vice-President's Critical Assessment-Prof. Joshua Jortner]

These goals rest on the statutory objectives and should define the missions of IUPAC.

1 Serving as an international, nongovernmental, scientific, authoritative and objective advisory body for global issues related to pure and applied chemistry.

2 Contributing to the advancement, coordination and collaboration of world-wide academic and industrial research in chemistry.

3 Providing effective channels of communication in the international chemistry community.

4 Promoting the service of chemistry to society and to the international community.

5 Contributing to education in chemistry on all levels.

6 Encouraging young chemists in developed and developing countries.

7 Advancing the service of chemistry to developing countries.

8 Broadening the geographical base of the Union

9 Addressing globally important issues of chemistry.

10 Advancing the public understanding of science in the special context of chemistry.

11 Serving as the 'voice of chemistry'.

12 Enhancing the visibility of the activities of the Union for the sake of the discipline.

13 Maintaining the norms, values, standards and ethics of science.

Although not explicitly incorporated in the bylaws, issues 10-13 are central for the international chemistry community and for the impact of science on society.

The Goals of IUPAC, an Ethically Based International Scientific Union [excerpted from paper by Prof. Pieter Steyn]

Inwardly directed Goals (traditional goals)

1 Serving as the leading (or representative) interna- tional, authoritative and objective advisory body for globally important issues related to the practice of pure and applied chemistry.

2 Contributing to the advancement, co-ordination and collaboration of world-wide academic and industrial research in chemistry.

3 Facilitating effective channels of communication in the international chemistry and scientific community.

Outwardly directed Goals (Service to the Society at Large)

1 Promoting universal access to the benefits of chemistry through formal, non-formal and informal education.

2 Contributing to the advancement of education in all aspects of chemistry in terms of quality and appropriateness.

3 Promoting chemical industry in its contribution to sustainable development, wealth creation, and the improvement of the quality of life. [Wealth creation may be omitted].

IUPAC Mission and strategic thrusts [excerpted from paper by Prof. Upendra Pandit]

IUPAC Mission: To advance and contribute to all international aspects of chemistry and to serve the interests of the international chemical community in the 21st century

Strategic thrusts:

IUPAC in the service of man

1.1 Respond to the evolving developments in Chemistry, especially with reference to interdisciplinary areas

1.2 Foster the positive image of chemistry as the 'MOLECULAR BASIS OF HUMAN WELFARE IN THE 21st CENTURY'

1.3 Initiate activities in areas of global concern where Chemistry can help to provide visible solutions on a short to medium time-scale basis [environment, ecology, bio-diversity, international aspects of health care, etc.]

1.4 Develop Programs directed to the specific needs of technically less-developed countries

IUPAC in the service of chemists

2.1 Establishment of international chemical standards, terms, codification and nomenclature-where it can be done effectively by the IUPAC

2.2 Development of Forums and Channels for Exchange of information on 'Educational Methods' 
2.3 Coordination of Technical Training (setting-up an International data-bank on available training positions and applicants, e.g. on postdocs)

2.4 Facilitate International Industrial Partnerships (databank on 'effective' academic, industrial and other laboratories which can do contract-work on specific projects)

2.5 Establish an IUPAC Information Centre to which chemists, affiliates and non-affiliates alike, can address their enquiries

2.6 Establish 'Name' Awards, Lectures and Fellowships for young chemists

The contribution of IUPAC in these areas is warranted on the basis of its Global Position, International Recognition and Available Expertise.

\section{Appendix 3. Organization and manage- ment of IUPAC's scientific work}

During the last few years there has been intensive study, discussion and debate within the Union on what was first termed 'restructuring' but later broadened to the more general 'Scientific Policy of the Union.' A number of proposals have been advanced, some have been adopted, some have been rejected outright and others have been declined for the present but might be introduced at a future date. Concurrently, during the last year, there have been increased efforts to address the overall mission and strategy of the Union, partially with advice from leading chemists outside IUPAC. These broader ideas have been focused in Vice-President Jortner's Critical Assessment (VPCA), which presents recommendations for establishing overall Goals and for expanding the scope and emphasis of IUPAC's scientific work. The present document complements the VPCA in addressing questions of organization and management of the scientific work.

Within the last two years, three of our seven Divisions have been or are being restructured to create Divisions of (i) Chemistry and the Environment, (ii) Chemistry and Human Health and (iii) Macromolecular Chemistry and Materials [name subject to modification]. Although further restructuring at the Division level is certainly possible, it has been decided as a result of discussions within the last year that the remaining four Divisions will in the near future retain their traditional scope of Physical, Inorganic, Organic and Analytical Chemistry. However, at the level of the Division Presidents and the Executive Committee, there is a strong consensus that additional flexibility is needed to tackle projects within a specific and limited time frame and to address problems that cross traditional boundaries within chemistry and between chemistry and other disciplines.

\section{Some historical perspective}

Most of the scientific work of the Union emanates from Commissions, augmented in many instances by Division Subcommittees, Working Parties and Task Forces. Over the years IUPAC has established a network of Commissions (currently numbering 37 ). Occasionally a new Commission is formed, sometimes there is a change in the name and/or terms of reference of a Commission and (quite infrequently) a Commission is abolished. Overall, there has evolved an organization that has the virtue of stability but the shortcomings of a static structure. Yet, the Statutes and Bylaws anticipate a more dynamic composition of Commissions. Statute 10.4 states: 'Each Division and Section may include such Commissions as are approved by the Council', while Bylaw 4.301 prescribes a detailed procedure for analyzing the need for a new Commission, including a report to Council. B 4.301 concludes: 'This report, if favourable to the creation of a new body [Commission], shall contain an indication as to the probable duration of the life of the new body and an estimate of its annual cost.' [Emphasis added] Bylaw 4.302 states: 'At each General Assembly, the Council shall in the light of the Division or Section President's report and on the recommendation of the Bureau decide whether or not to continue each Commission.' [Emphasis added]

In spite of the flexibility built into the Statutes and Bylaws, the structure has been largely static. As long ago as 1955, President Tiselius observed that '... many of our Commissions do very fine work and have justified their existence beyond any doubt...Perhaps it would be practical to introduce a distinction between standing Commissions and Commissions set up for a definite, limited task. The second type should be limited in their mandate to, for example, two years (that is to say, between two Conferences of the Union), and should be given opportunities to meet within this period. Their task would, of course, be entirely different from that of a standing Commission which involves maintaining a more or less continuous survey of a given field and taking action whenever necessary.' Yet, such limited lifetime Commissions have been formed only once-as an interim measure to postpone or avoid the creation of more permanent Commissions-and few Commissions have been abolished. In 1973, President Bénard pointed out why this is the case: 'It is easy to obtain general approval for the creation of new bodies, but it is difficult to decide to abandon existing ones. The reason for this is that it takes far more courage to say 'no' than to say 'yes', particularly when the consequences involve our friends.' He went on to say: 'An institution which does not have the strength to renew itself is an institution condemned at length to sterility.' 
The current concerns on restructuring stem from 1981, when President Zollinger made the first real 'critical assessment' of IUPAC projects. According to his analysis, the problems seemed to stem from '(1) inefficiency and too long duration of a relatively large number of projects; (2) insufficient use of our traditional means to solve problems in a changing world; (3) the involvement of too small a circle of chemists in IUPAC work-a reporter in Davos even called this circle a 'charmed circle'.' Sixteen years after Zollinger's appraisal, and after a series of initiatives to correct these perceived deficiencies, we have many more projects than Zollinger had to contend with, the traditional means are not working well, and we still have a 'charmed circle.'

Let's be clear: Even with these shortcomings, IUPAC Commissions have done and continue to do outstanding work for the international chemical community. Our challenge is to insure that such high quality work continues but that the projects undertaken are widely regarded as relevant to today's world and are completed in a time frame consistent with the fast pace of modern research and industrial development. We must reach out to a broad international community of chemists to help define the needs on which IUPAC projects are based and to recruit the most talented chemists worldwide to work on these projects. As evidenced by the quotes from 1955, 1973 and 1981, it has not been possible to achieve the dynamism needed within our present structure and mode of operation. We need to convert from a primarily static Commission structure to one that is largely based on time-limited Commissions formed to carry out specific, well defined tasks.

\section{Philosophical basis for a new organization}

Under this concept, the IUPAC organization would continue to consist of Council, Bureau, Standing Committees and Divisions (including Division Committees). However, the norm would be that Commissions should not be regarded as part of the 'regular' organization but rather as the temporary working groups that carry out specific projects developed by the Division Committees with the help of the Governance and the Secretariat. There may be areas in which continuity is needed, such as organization of a regular series of symposia. Such activities might now be carried out by a Commission, but a continuing Subcommittee of the Division Committee could take over such functions.

Divisions should regard the entire world-wide chemical community as the resource for both ideas and for volunteers to carry out projects, not the 'charmed circle' of IUPAC insiders. Likewise, ideas for projects should come from the world-wide community. Just how to generate such ideas, develop projects and seek out people able and willing to work on the projects is, of course, the key to success or failure. I am convinced that ideas for useful work usually originate in a 'bottoms-up' manner, not as directed from 'top-down'. In fact, the establishment of the pool TMs was to permit the undertaking of such 'top-down' projects generated outside the mainstream of Commission activity, but after several years there are very few such projects. If we implement the type of structure envisioned here, but without a good mechanism to identify and develop projects-and to secure the services of experts on the Commissionswe will kill the useful work that is now being done. A great deal of thought and planning is needed to insure that IUPAC can develop the processes to do this without the large cadre of long-term members of Commissions. I do not pretend to have the answers, but I think that the following steps would be desirable:

- Insure through the nomination process that the members of the Division Committees are people with a broad outlook in their discipline. This will help in generating ideas and in finding good people to work on Commissions.

- Include on Division Committees (wherever possible) editors of major journals, who have databases of potential project referees and Commission members. Also, editors may be more aware than the average chemist of areas in which IUPAC work on standardization, terminology, etc. is really needed.

- Establish close relations between the professional staff of the Secretariat and national chemical societies and NAOs to identify potential workers.

- Use IUPAC-sponsored symposia more effectively to advertise IUPAC activities and to solicit ideas for projects through brainstorming sessions at such symposia. The Secretariat should play a stronger role than it now does in the arrangements for symposia, and a staff member could attend to note what ideas are generated.

- Ask Division Committees to organize planning meetings of carefully chosen people to evaluate the need for a Commission in a given field or to define a project and suggest Commission members.

- Insure that a real refereeing system is in place for projects proposed by members of Division Committees or members of any existing Commission.

Under this concept, each Commission would have a defined task with a defined product and a defined time in which to carry out the project, along with a budget, expressed in dollars, not Titular Members. It would be expected that the members of a Commission which has completed its task will consider their current active involvement in IUPAC to be over until they are asked to serve on a new Commission. Clearly, some people who distinguish themselves on such projects may also be 
asked to serve on Division Committees or in some other capacity, but there should be no general expectation of a long-term active involvement. However, creation of an IUPAC Fellows Program [as will be proposed to Council in Geneva] would, over the course of time, insure that anyone who has ever worked on any IUPAC activity or project would have the opportunity to remain in touch with current activities and to make suggestions for new projects and Commission members.

\section{Proposed course of action}

The first step, completed at the Executive Committee in Jerusalem, was to discuss the ideas articulated here and to integrate those with proposals from individual Divisions and with aspects of the VPCA. The EC endorsed the concept of an organization based primarily on time-limited Commissions but recognized that implementation will be dependent on solving a number of problems, some of which are given above.

The EC also endorsed in principle the recommendations in the VPCA to establish clear Goals for IUPAC but, again, recognized that further thought and discussion are needed to refine the Goals. The EC concluded that a broad-based committee would be needed to develop the necessary strategic thrusts and to consider their implementation in terms of the structure and guidelines for scientific activity. The EC therefore authorized the formation of a Strategy Development and Implementation Committee (SDIC), to report back to the EC in April 1998. From the findings and recommendations of the SDIC, the EC expects to formulate specific proposals for approval by the Bureau in September 1998 and for necessary action by Council in 1999.

The examination of these issues by the SDIC and the possible implementation of broad changes in goals, structure and operation of IUPAC and its constituent parts should not negate actions currently underway in and between several Divisions to effect a number of specific structural and functional changes during 1997.

Edwin D. Becker, Secretary General

\section{Appendix 4. Selected bylaws}

\section{B4.1 Division and Section Committees}

B4.101 Each Division or Section shall be administered by a Division or Section Committee which shall be the organ of liaison between the Bureau on the one hand and the various bodies constituting the Division or Section on the other hand.

B4.102 The Titular Members and Associate Members of a Division or Section Committee and of Commis- sions within a Division or Section shall together form the Membership of the Division or Section.

B4.103 The Titular Members of each Division or Section Committee shall be elected by the Membership of the Division or Section according to its rules and shall not exceed 10 Titular Members, unless otherwise determined by the Bureau. The term of service of a Titular Member shall be not more than four consecutive years, but shall cease on election as an officer. The Vice-President and the President of a Division or Section shall not hold these respective offices for more than four consecutive years; the Secretary of a Division or Section shall serve for four consecutive years and be eligible for reelection up to a maximum of a further four years. Exceptional circumstances must be established and special permission of the Bureau granted for Titular Membership of the same or more than one Division or Section Committee beyond a total of 12 years whether the Titular Memberships are consecutive or not.

Subject to this provision the immediate PastPresident of the Division or Section shall be one of the Titular Members of the Division or Section Committee for a period of two years. In addition to these Titular Members the President, Vice-President, Secretary General, and Treasurer of the Union shall be ex officio Members of all Division and Section Committees.

Additionally a Division or Section Committee may elect Associate members, who shall have full voting rights. The number of Associate members shall not exceed six. The term of service of an Associate Member shall be two years, with the possibility of reelection consecutively for two more years only.

A newly elected Titular Member or Associate Member of a Division or Section Committee shall assume office only after approval by the Bureau or Executive Committee. The Adhering organization with which the Titular Member or Associate member is connected shall be notified of the appointment.

B4.104 The Division or Section Committee shall elect from among its existing and, subject to confirmation, new Titular Members a President, a Vice-President designated as President-Elect, and a Secretary. These elections shall be subject to approval by the Council.

B4.105 The Division or Section Committee may form a Division or Section Executive Committee, consisting of the President, the Vice-President designated as President-Elect, and the Secretary of the Division or Section, to carry out the necessary administrative 
duties between meetings of the Division or Section Committee.

B4.106 The functions of the Division or Section Committee shall be:

B4.1061 to propose to the Council through the Bureau the establishment of Commissions to be attached to it and to appoint the membership and the initial officers of these, the appointments having to be approved by the Council;

B4.1062 to propose to the Council through the Bureau the dissolution of existing Commissions when required;

B4.1063 to supervise the work of its Commissions and other bodies;

B4.1064 to plan and organize scientific meetings and other activities which are deemed useful in furthering the objects of the Division or Section;

B4.1065 to prepare a budget for the Division or Section in accordance with a procedure to be prescribed by the Treasurer, for consideration and approval by the Bureau and the Council;

B4.1066 to advise the Bureau for recommendation to the Council on scientific matters.

B4.107 The Division or Section Committee shall meet at least every two years, during a General Assembly.

B4.108 Decisions of the Division or Section Committee must receive the approval of the Bureau when they would have financial consequences involving the budget of the Union. In addition, in order to ensure the fullest coordination between the activities of all the Divisions and Sections the Secretary General at the Secretariat shall be informed of all other decisions taken by the Division and Section Committee.

B4.109 At a General Assembly the Division or Section President shall report to the Council on the activities of the Division or Section since the last General Assembly. In a year in which a General Assembly is not held the Division or Section President shall present to the Division or Section Committee and to the Bureau a written report on the activities of the Division or Section since the last General Assembly.

B4.110 Each Division and Section shall make provision for the conduct of the work of its Commissions and other bodies. Such provision, which must receive the approval of the Bureau, may be incorporated in Divisional or Sectional rules.

\section{B4.3 Commissions}

B4.301 On the recommendation of a Division or Section Committee, through the Bureau, the Council may create a Commission of the Division or Section. Each Commission shall have as its object the study of topics of international scientific or technical significance requiring agreement, regulation, standardization, or codification in some aspect of pure or applied chemistry. The terms of reference of a new Commission shall be clearly described and approved by the Council. If a Division or Section Committee wishes to create a Commission, it must apply to the Bureau for the appointment of an ad hoc committee of three persons which shall study the question and then report back to the Bureau. This report, if favourable to the creation of a new body, shall contain an indication as to the probable duration of the life of the new body and an estimate of its annual cost.

B4.302 At each General Assembly, the Council shall in the light of the Division or Section President's report and on the recommendation of the Bureau decide whether or not to continue each Commission.

B4.305 (in part) Besides the Membership of a Commission the following may attend Commission meetings:

(i) National Representatives nominated by the various Adhering organizations and approved by the Commission. A Commission may coopt not more than one such representative from an Adhering organization, but such representation shall not be permitted if the Commission already has a Titular or Associate Member from that Organization, unless exceptional circumstances are established and special permission granted by the Bureau. Such representation shall lapse at the conclusion of the next General Assembly unless the person is renominated by his Adhering organization and reapproved by the Commission. Reappointment of National Representatives beyond a total of 12 years service, whether these are consecutive or not, requires that special circumstances should be established by the Adhering organization.

B4.307 Titular Members of Commissions have the right to receive contributions towards travel and subsistence expenses from funds of the Union as authorized by the Treasurer acting on behalf of the Union. Contributions may be made to Associate Members or members of subcommittees on recommendation of the Division or Section President and with the agreement of the Treasurer. 